\title{
Effect of high gold salt concentrations on the size and polydispersity of gold nanoparticles prepared by an extended Turkevich-Frens method
}

\author{
Kara Zabetakis • William E. Ghann • Sanjeev Kumar • \\ Marie-Christine Daniel \\ Published online: 23 October 2012 \\ (C) The Author(s) 2012. This article is published with open access at Springerlink.com
}

\begin{abstract}
The Turkevich-Frens synthesis starting conditions are expanded, ranging the gold salt concentrations up to $2 \mathrm{mM}$ and citrate/gold(III) molar ratios up to $18: 1$. For each concentration of the initial gold salt solution, the citrate/gold(III) molar ratios are systematically varied from $2: 1$ to $18: 1$ and both the size and size distribution of the resulting gold nanoparticles are compared. This study reveals a different nanoparticle size evolution for gold salt solutions ranging below $0.8 \mathrm{mM}$ compared to the case of gold salt solutions above $0.8 \mathrm{mM}$. In the case of $\left[\mathrm{Au}^{3+}\right]<0.8 \mathrm{mM}$, both the size and size distribution vary substantially with the citrate/gold(III) ratio, both displaying plateaux that evolve inversely to $\left[\mathrm{Au}^{3+}\right]$ at larger ratios. Conversely, for $\left[\mathrm{Au}^{3+}\right] \geq 0.8 \mathrm{mM}$, the size and size distribution of the synthesized gold nanoparticles continuously rise as the citrate/gold(III) ratio is increased. A starting gold salt concentration of $0.6 \mathrm{mM}$ leads to the formation of the
\end{abstract}

Kara Zabetakis and William Ghann contributed equally to this work.

Electronic supplementary material The online version of this article (doi:10.1007/s13404-012-0069-2) contains supplementary material, which is available to authorized users.

K. Zabetakis $\cdot$ W. E. Ghann • M.-C. Daniel $(\bowtie)$

Department of Chemistry and Biochemistry,

University of Maryland, Baltimore County,

Baltimore, MD 21250, USA

e-mail:mdaniel@umbc.edu

K. Zabetakis

e-mail:kzab@umd.edu

W. E. Ghann

e-mail:wghann1@umbc.edu

S. Kumar

Department of Chemical Engineering, Indian Institute of Science,

Bangalore 560012, India

Present Address:

K. Zabetakis

School of Civil and Environmental Engineering,

University of Maryland, College Park,

Baltimore, MD 20742, USA most monodisperse gold nanoparticles (polydispersity index $<$ 0.1 ) for a wide range of citrate/gold(III) molar ratios (from 4:1 to 18:1). Via a model for the formation of gold nanoparticles by the citrate method, the experimental trends in size could be qualitatively predicted: the simulations showed that the destabilizing effect of increased electrolyte concentration at high initial $\left[\mathrm{Au}^{3+}\right]$ is compensated by a slight increase in zeta potential of gold nanoparticles to produce concentrated dispersion of gold nanoparticles of small sizes.

Keywords Gold nanoparticles · Synthesis · Citrate reduction $\cdot$ High concentration

\section{Introduction}

The synthesis of colloidal gold via citrate reduction was first introduced by Turkevich et al. in 1951 [1], and was later refined by Frens in the 1970s [2, 3]. This citrate reduction method is also reviewed in Hayat's book on colloidal gold, along with the other well-known techniques for preparing gold nanoparticles of different sizes (using reducing agents such as white phosphorus, sodium borohydride, ascorbic acid) [4]. The citrate reduction process involves hot gold chloride and sodium citrate as reactants. In this reaction, the citrate molecules act as both reducing and stabilizing agents, allowing for the formation of the colloidal gold [5]. The synthesis process typically creates gold nanoparticles (GNPs) in the 10-150-nm size range with two major disadvantages: this technique produces very dilute GNP solutions $\left(\left[\mathrm{Au}^{3+}\right] \leq 0.25 \mathrm{mM}\right)[6]$ and the size distribution broadens with increase in particle size, leading to polydisperse GNPs for sizes over $50 \mathrm{~nm}$.

Gold nanoparticles display a variety of properties [7] and have important applications as diverse as cosmetics [8], electronics [9], therapeutics [10-12], imaging [13, 14], drug delivery $[15,16]$, and pollution remediation $[17,18]$. The 
mentioned applications often call for monodisperse nanoparticles of a particular size in large quantities and/or at high concentrations $[19,20]$. Therefore, it is important to understand how changes in the synthesis conditions can affect the nanoparticle characteristics.

Variations of the Turkevich-Frens method have been investigated in the past years. Ji et al. [5] have demonstrated that molar ratios of citrate to gold(III) salt $(\mathrm{Ct} / \mathrm{Au})$ higher than 3:1 raise the $\mathrm{pH}$ of the reaction mixture $(\mathrm{pH}>6.5)$, a condition that favors the formation of monodisperse GNPs. They also have observed that the diameter of the obtained GNPs levels off at very high citrate to gold(III) molar ratios $(\mathrm{Ct} / \mathrm{Au} \geq 14: 1)$ [5]. Puntes group [21] and Sivaraman et al. [22] have shown that if the sequence of the addition of citrate and gold chloride is reversed, the GNPs formed are smaller and narrower in size distribution. Moreover, gold salt concentrations much higher than $0.25 \mathrm{mM}$ have been studied by other groups. Kimling et al. [6] have noticed a significant increase in size (as well as in polydispersity) of the GNPs obtained from gold salt solutions with concentrations higher than $0.8 \mathrm{mM}$ and $\mathrm{Ct} / \mathrm{Au}$ ratios $<2$. Li et al. [23] have reported the formation of concentrated GNP solutions $\left(\left[\mathrm{Au}^{3+}\right]=2.5 \mathrm{mM}\right)$ with narrower size distributions by adjusting the $\mathrm{pH}$ and temperature of the reaction mixtures. Along with the decrease in polydispersity, a decrease of the diameter of the formed GNPs has also been observed [23].

Herein, by expanding the conditions of the Turkevich-Frens synthesis, we report a systematic study regarding the evolution of both size and size distribution of the GNPs formed, when the concentration of initial gold salt solutions and their respective citrate/gold(III) ratios are increased. To examine these trends, GNP solutions have been made under different starting conditions: a series of seven gold salt concentrations (ranging from 0.3 to $2 \mathrm{mM}$ ) have been investigated, and $\mathrm{Ct} / \mathrm{Au}$ molar ratios from 2:1 to 18:1 have been studied. The sizes and polydispersity indices (PDI) of resulting gold nanoparticles have been measured via dynamic light scattering (DLS) spectroscopy and analyzed to assess for trends in the particle sizes and size distributions. The concentration of the starting gold solution is found to have a significant effect on the size and PDI of the formed nanoparticles. Simulations have also been performed in order to better understand these observations.

\section{Experimental}

\section{Materials/chemicals}

Tetrachloroauric acid monohydrate $\left(\mathrm{HAuCl}_{4} \mathrm{H}_{2} \mathrm{O}, 99.9 \%\right.$ assay) and trisodium citrate dihydrate ( $99.9 \%$ assay) were purchased from Electron Microscopy Services (Fort Washington, PA). These chemicals were used without further purification. The TEM carbon-coated 200-mesh copper grids were also purchased from Electron Microscopy
Services. All glassware used for GNPs syntheses was cleaned with freshly prepared aqua regia solution (three parts $\mathrm{HCl}$, one part $\mathrm{HNO}_{3}$ ) and rinsed with Milli-Q water (18 $\mathrm{M} \Omega \mathrm{cm}$ resistivity). The same ultrapure water was used in the preparation of GNP solution and other aqueous solutions.

\section{Gold nanoparticle synthesis}

The GNP solutions were synthesized using a modified Frens method [5]. First, a gold salt stock solution was prepared using the entire content of a commercial vial with an average of $0.1 \mathrm{~g}$ of chloroauric acid. The content of the vial was accurately weighed and dissolved in $10.0 \mathrm{~mL}$ of pure water (Millipore Milli-Q). Next, a $5 \%$ citrate aqueous stock solution $(0.17 \mathrm{M})$ was prepared using trisodium citrate. The accurate molarities of the gold salt and sodium citrate solutions were calculated. An accurately measured quantity of the gold salt solution (calculated based on the desired concentration of gold) was then transferred to a $100-\mathrm{mL}$ volumetric flask with a micropipette (Gilson). The concentration of gold chloride solution was varied from 0.3 to $2 \mathrm{mM}$. All $100 \mathrm{~mL}$ of the chloroauric acid solution was then transferred to a three-neck round bottom flask equipped with a stir bar. Next, a micropipette was used to accurately transfer a portion of the $5 \%(0.17 \mathrm{M})$ sodium citrate solution (that was calculated from the desired molar ratio of sodium citrate to gold salt) to a separate vial. The molar ratios of citrate to gold(III) ranged from 2:1 to 18:1. The vial was then set aside for later use. The three-neck round bottom flask containing both the gold salt solution and a stir bar was equipped with a condenser and placed in a hot oil bath. The stirring speed was increased until a vortex was noticed. When the reflux started, the citrate solution from the vial was quickly poured into the round bottom flask. Then, the reaction was allowed to run for no less than $20 \mathrm{~min}$, but no more than $30 \mathrm{~min}$. In other words, the reaction was allowed to run until a deep ruby red color was observed; otherwise, the reaction was stopped after $30 \mathrm{~min}$. The reaction was observed to go to completion by one of two visual pathways: the gold chloride solution went either (1) from yellow to black to ruby (for low $\mathrm{Ct} / \mathrm{Au}$ ratios) or (2) from yellow to pale pink to ruby (for high $\mathrm{Ct} / \mathrm{Au}$ ratios). The hue and intensity of the final ruby color of the particle solution depended on the initial gold salt concentration and on the $\mathrm{Ct} / \mathrm{Au}$ ratio.

\section{DLS measurements}

Samples from the obtained GNP solutions were analyzed by DLS spectroscopy to quantify the average hydrodynamic diameter (Zave) and PDI. DLS measurements were performed with a Malvern Zetasizer Nano ZS (Malvern, Southborough, MA) equipped with a $633-\mathrm{nm} \mathrm{He}-\mathrm{Ne}$ laser and operating at an angle of $173^{\circ}$. The software used to collect and analyze the data was the Dispersion Technology Software version 5.02 
from Malvern. The GNP solutions were stored securely in a hood. These stored solutions have been monitored by DLS over a period of up to 3 months, with an average of four DLS measurements for each stored solution. All the DLS measurements have been then averaged for each individual GNP solution, and the resulting Zave and PDI have been recorded.

Model

The model used for predictions of the GNPs sizes was the model of Kumar et al. [24], taking into consideration the role of coagulation during the synthesis of citrate-stabilized GNPs. For the lower range of $\left[\mathrm{Au}^{3+}\right]$ studied here $(0.3$ to $0.6 \mathrm{mM}$ ), the original model (published in 2007) was first used to obtain predictions. Then, in order to better correlate with the experimental data, the expression of the surface potential in the original model was modified by changing the prefactor in this expression: the value 90 was replaced by 95 and 100, respectively and two new sets of predictions were obtained for the GNPs sizes.

\section{Results and discussion}

To date, the previous studies on the formation of GNPs based on the Turkevich-Frens method have mostly involved lower initial concentrations of gold salts $(\leq 0.25 \mathrm{mM})$. The use of higher concentrations of gold salts has received little attention and their effect on the size of the formed GNPs has not been systematically investigated. Herein, we report the study on the formation of GNPs, starting with a series of gold salt concentrations ranging from 0.3 to $2 \mathrm{mM}$ and using $\mathrm{Ct} / \mathrm{Au}$ molar ratios ranging from $2: 1$ to $18: 1$ for each of these concentrations. DLS spectroscopy has been used to

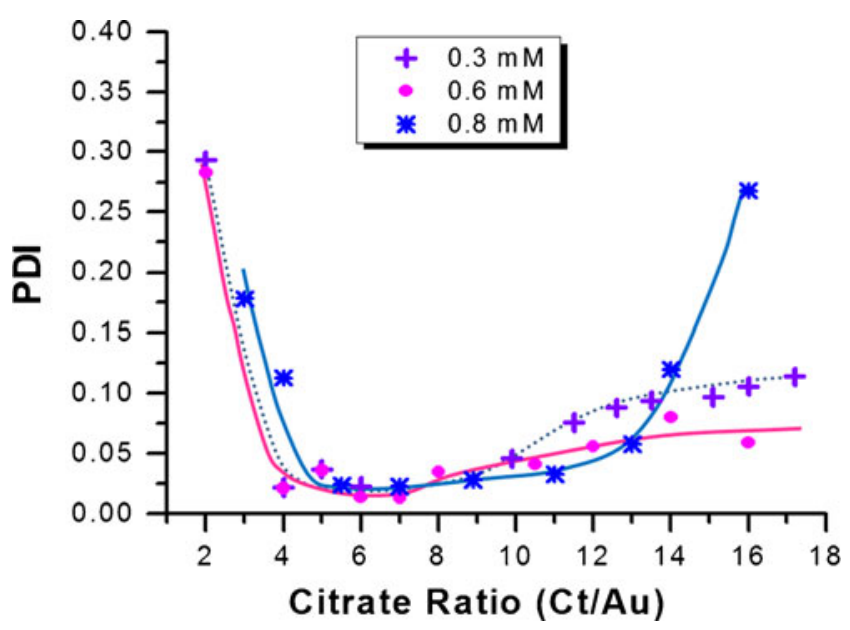

Fig. 1 GNP polydispersity vs citrate ratio for gold chloride concentrations $\leq 0.8 \mathrm{mM}$. The lines are guides for the eye

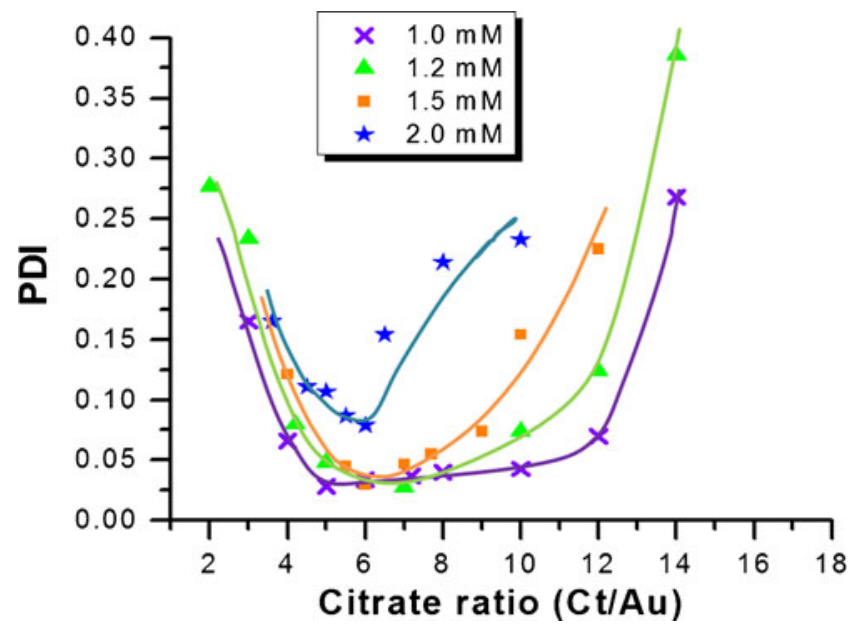

Fig. 2 GNP polydispersity vs citrate ratio for gold chloride concentrations $>0.8 \mathrm{mM}$. The lines are guides for the eye

measure the hydrodynamic diameter (HD) and the PDI of each prepared GNP solution.

Effect of the initial gold salt concentration on the GNP size distribution

Figures 1 and 2 present the trends of the PDI of the obtained GNPs with respect to the $\mathrm{Ct} / \mathrm{Au}$ ratio for different concentrations of gold salt. In the case of starting gold chloride solutions of 0.3 and $0.6 \mathrm{mM}$, the PDI of the formed GNPs decreases as $\mathrm{Ct} / \mathrm{Au}$ is increased from 2:1 to $4: 1$ and remains low (between 0.02 and 0.1 ) for higher $\mathrm{Ct} / \mathrm{Au}$ ratios (up to 17:1) (Fig. 1). However, the $0.8 \mathrm{mM}$ gold salt solutions lead to GNPs with increasing PDI for $\mathrm{Ct} / \mathrm{Au}$ ratios higher than 13:1 (Fig. 1). Also, when using more concentrated gold chloride solutions (up to $2 \mathrm{mM}$ ), the resulting GNPs present a low PDI for a range of citrate/gold(III) ratios that shrinks as the concentration of gold salt increases (Fig. 2). For instance, the $0.8 \mathrm{mM}$ gold chloride solution forms monodisperse GNPs (PDI $<0.1)[25,26]$ for a range of $\mathrm{Ct} / \mathrm{Au}$

Table 1 Ranges of $\mathrm{Ct} / \mathrm{Au}$ ratios that can be used to form monodisperse GNPs at different $\left[\mathrm{Au}^{3+}\right]$

\begin{tabular}{lll}
\hline $\begin{array}{l}\text { Initial } \\
{\left[\mathrm{Au}^{3+}\right]} \\
(\mathrm{mM})\end{array}$ & $\begin{array}{l}\text { Range of Ct/Au molar ratios } \\
\text { leading to monodisperse } \\
\text { GNPs }(\mathrm{PDI}<0.1)\end{array}$ & $\begin{array}{l}\text { Range of } \mathrm{Ct} / \mathrm{Au} \text { molar } \\
\text { ratios leading to formation } \\
\text { of GNPs }(\mathrm{PDI}<0.2)\end{array}$ \\
\hline 0.3 & $3.2-13.5$ & $3->17$ \\
0.6 & $3.5->17$ & $3->17$ \\
0.8 & $4.5-13.5$ & $3.5-14.5$ \\
1 & $4-12.5$ & $3.5-13$ \\
1.2 & $4.5-11$ & $4-12$ \\
1.5 & $4.5-9$ & $4-10.5$ \\
2 & $5-6$ & $4-7.5$ \\
\hline
\end{tabular}


ratios from 4:1 to $13: 1$, whereas only a very narrow range of $\mathrm{Ct} / \mathrm{Au}$ ratios $(5: 1$ to $6: 1)$ produces monodisperse GNPs when starting with $2.0 \mathrm{mM}$ gold chloride solutions (Table 1). From these data, we can conclude that, depending on the starting concentration of gold salt, a wider or narrower range of $\mathrm{Ct} / \mathrm{Au}$ ratios allows for the formation of monodisperse GNPs. This way, by choosing the appropriate $\mathrm{Ct} / \mathrm{Au}$ ratios, it is possible to generate concentrated solutions of monodisperse GNPs. Also, it can be noted that an initial gold chloride concentration of $0.6 \mathrm{mM}$ results in the formation of the most monodisperse GNPs (with PDIs down to 0.03) for the widest range of citrate/gold(III) ratios (from 3.5:1 and up) (Table 1).

Effect of the initial gold salt concentration on the GNP diameter

When varying the initial gold chloride concentration, we find that the size evolution of the formed GNPs follows different trends (as a function of the $\mathrm{Ct} / \mathrm{Au}$ ratios) for gold salt concentrations in the range below $0.8 \mathrm{mM}$ (Fig. 3) and in the range above $0.8 \mathrm{mM}$ (Fig. 4).

The GNPs synthesized from 0.3 and $0.6 \mathrm{mM}$ gold salt solutions display large hydrodynamic diameters (HD was around 32 and $27 \mathrm{~nm}$, respectively) when a $\mathrm{Ct} / \mathrm{Au}$ ratio of $2: 1$ is used (Fig. 3). The GNPs then rapidly decrease in size and reach a minimum diameter for $\mathrm{Ct} / \mathrm{Au}$ ratios of $4: 1$ and 5:1, for 0.3 and $0.6 \mathrm{mM}$ gold salt solution, respectively, and slowly increase back in size for higher ratios of citrate to gold, finally leveling off at high $\mathrm{Ct} / \mathrm{Au}$ ratios (>14:1). A similar behavior of the size evolution as a function of $\mathrm{Ct} / \mathrm{Au}$ ratio has already been reported by $\mathrm{Ji}$ et al. for gold chloride solutions of $0.25 \mathrm{mM}$ [5]. Although the evolution of the GNP sizes follows similar trends for 0.3 and $0.6 \mathrm{mM}$ gold

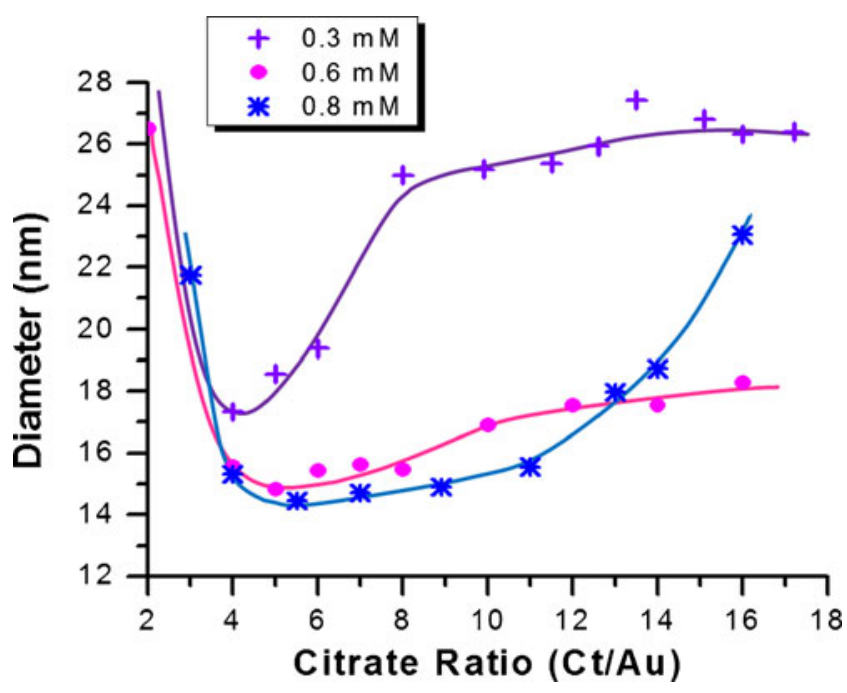

Fig. 3 GNP size vs citrate ratio for gold chloride concentrations $\leq$ $0.8 \mathrm{mM}$. The lines are guides for the eye

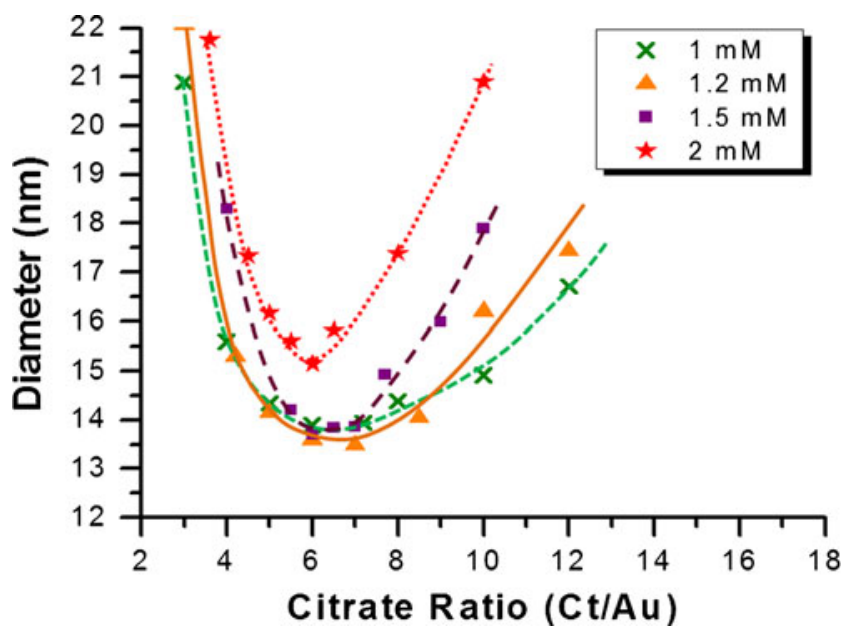

Fig. 4 GNP size vs citrate ratio for gold chloride concentrations $>$ $0.8 \mathrm{mM}$. The lines are guides for the eye

salt solutions, the GNPs obtained from $0.6 \mathrm{mM}$ gold salt solutions present smaller diameters than when using $0.3 \mathrm{mM}$ gold salt solutions, for the same $\mathrm{Ct} / \mathrm{Au}$ ratios. This size difference is even more pronounced when reaching the plateau at higher $\mathrm{Ct} / \mathrm{Au}$ ratios. For instance, the HD trend of GNPs prepared from $0.3 \mathrm{mM}$ gold salt solutions levels off at diameters of around $26 \mathrm{~nm}$, while it levels off at diameters of around $18 \mathrm{~nm}$ when starting with $0.6 \mathrm{mM}$ gold chloride solutions. Likewise, $0.3 \mathrm{mM}$ gold salt solutions lead to GNPs with sizes reaching a plateau of around $26 \mathrm{~nm}$, which is lower than the plateau reported for GNPs from $0.25 \mathrm{mM}$ gold chloride solutions (HD>30 nm, Peng's data [5]). These results indicate that, for the gold salt concentration range below $0.8 \mathrm{mM}$, higher concentrations of gold salt lead to a plateau with smaller GNP sizes. The size plateaus at large $\mathrm{Ct} / \mathrm{Au}$ ratios for low $\left[\mathrm{Au}^{+3}\right]$ because, for low gold salt concentrations (below $0.8 \mathrm{mM}$ ), the total electrolyte concentration is still low enough at high $\mathrm{Ct} / \mathrm{Au}$ ratios, so that there is no occurrence of coagulation which would lead to size increase. Also, for $\left[\mathrm{Au}^{3+}\right]<0.8 \mathrm{mM}$, the $\mathrm{pH}$ has a major effect on the GNP formation (vide supra), and Ji et al. [5] have shown that the stabilization of $\mathrm{pH}$ at high $\mathrm{Ct} / \mathrm{Au}$ ratios is associated to the plateau observed at these same ratios.

The size evolution found for GNPs prepared from $0.8 \mathrm{mM}$ gold salt solutions is intermediate between the trends observed with 0.3 and $0.6 \mathrm{mM}$ gold(III) solutions and the trends displayed with $\mathrm{Au}^{3+}$ solutions of $1 \mathrm{mM}$ and over. Indeed, $0.8 \mathrm{mM}$ gold salt solutions form smaller GNPs than with those of $0.6 \mathrm{mM}$ but only for $4<\mathrm{Ct} / \mathrm{Au}$ ratio $<13$. Also, the minimum size is reached for a $\mathrm{Ct} / \mathrm{Au}$ ratio of around 5:1-6:1, then increases very slowly until $\mathrm{Ct} / \mathrm{Au}$ ratios of around $11: 1$, as it was going to reach a plateau, but instead a sudden increase in $\mathrm{HD}$ is observed for $\mathrm{Ct} / \mathrm{Au}$ ratios $>13: 1$ (Fig. 3).

Figure 4 displays the HD of the GNPs formed from 1$2 \mathrm{mM}$ gold chloride solutions as a function of the $\mathrm{Ct} / \mathrm{Au}$ 
ratios used. Similar to the case of lower $\left[\mathrm{Au}^{3+}\right]$, the sizes of GNPs formed from 1-2 mM gold salt solutions first decrease as the $\mathrm{Ct} / \mathrm{Au}$ ratio is increased, reaching a minimum size at a ratio of around 6:1. However, the diameter range of the GNPs produced from gold salt solutions of $1 \mathrm{mM}$ up to $2 \mathrm{mM}$ does not level off at high $\mathrm{Ct} / \mathrm{Au}$ ratios, but instead shows a continuous increase (Fig. 4). Furthermore, the plot slopes of the decrease and then the increase in the GNP size (as $\mathrm{Ct} / \mathrm{Au}$ ratio increases) are becoming steeper as the concentrations of gold chloride increases, leading to larger GNPs from concentrated gold salt solutions at $\mathrm{Ct} / \mathrm{Au}$ ratios of $4: 1$ or 10:1. Also, the minimum $\mathrm{HD}$ obtained from $1,1.2$, and $1.5 \mathrm{mM} \mathrm{HAuCl}_{4}$ solutions remained around 13.5-14 $\mathrm{nm}$ (as well as from $0.8 \mathrm{mM} \mathrm{HAuCl}_{4}$ ), but it slightly increases to about $15 \mathrm{~nm}$ when $2 \mathrm{mM}$ gold salt solution is used.

In order to assess the reproducibility of the size trends observed when varying $\mathrm{Ct} / \mathrm{Au}$ ratios, we used initial gold salt solutions of $1.5 \mathrm{mM}$ as a representative example. We performed three gold nanoparticles syntheses in triplicates, using $\mathrm{Ct} / \mathrm{Au}$ ratios of 4:1, 6:1, and 10:1. The resulting sizes were plotted in Figure S1 of the Electronic supplementary material (ESM), along with their respective error bars. Good reproducibility was obtained, even at this high gold salt concentration. Although the presence of few aggregates could be detected by DLS for some of the experiments, filtration with $0.22 \mu \mathrm{m}$ filters eliminated any trace of aggregation.

To help visualize the difference in the GNP sizes obtained using same $\mathrm{Ct} / \mathrm{Au}$ ratios but different gold(III) concentrations, Figs. 5 and 6 present the HD of GNPs formed using different $\mathrm{Ct} / \mathrm{Au}$ ratios as a function of $\left[\mathrm{Au}^{3+}\right]$. As shown in Fig. 5, when the $\mathrm{Ct} / \mathrm{Au}$ ratio is increased from 2:1 up to 5:1, a general decrease of the GNP size is observed across the range of gold chloride concentrations studied here (except at $0.3 \mathrm{mM}$ $\mathrm{HAuCl}_{4}$, for which GNP sizes start increasing back for a Ct/ Au ratio of 5:1, since the minimum size is observed for a ratio

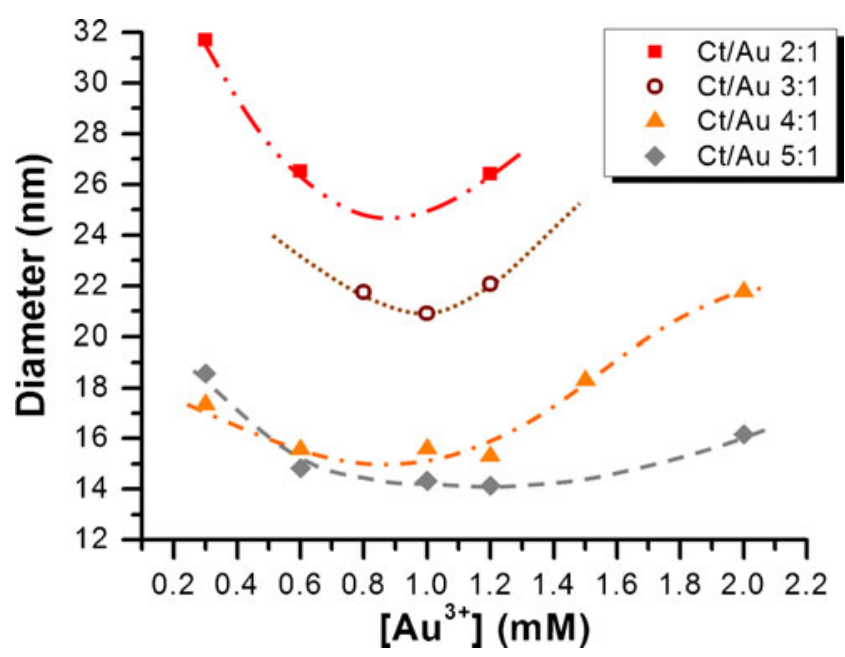

Fig. 5 GNP size vs gold(III) concentration for $2 \leq \mathrm{Ct} / \mathrm{Au}<6$. The lines are guides for the eye

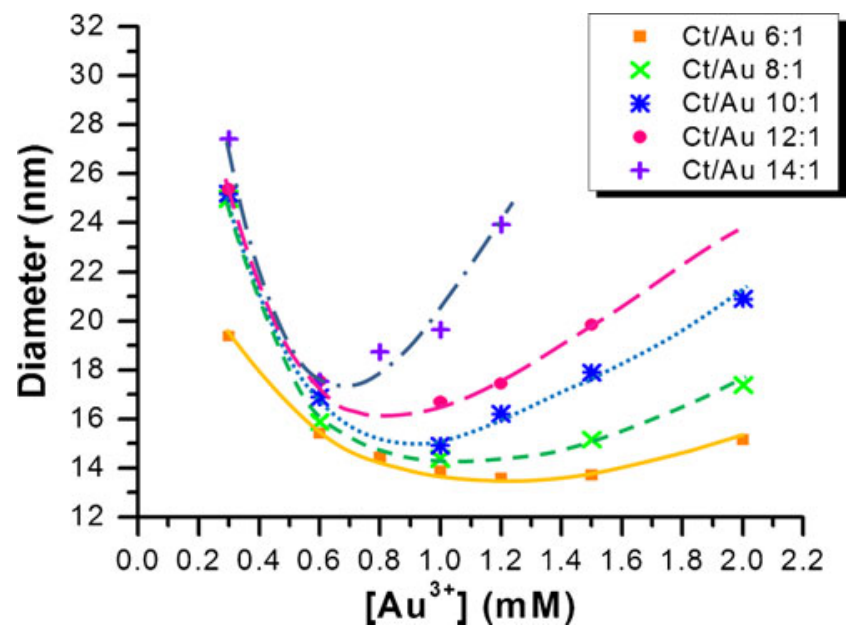

Fig. 6 GNP size vs gold(III) concentration for $\mathrm{Ct} / \mathrm{Au} \geq 6$. The lines are guides for the eye

of $4: 1$ at this concentration). For further increase of the $\mathrm{Ct} / \mathrm{Au}$ ratio from 6:1 to 14:1, the GNP size increases back for most of the concentrations, although this increase is minimal for gold concentrations below $0.8 \mathrm{mM}$ (Fig. 6).

On the other hand, for the same $\mathrm{Ct} / \mathrm{Au}$ ratio, different initial gold chloride concentrations give GNPs of different sizes (Figs. 5 and 6). For instance, for a $\mathrm{Ct} / \mathrm{Au}$ ratio of 10:1, $0.3 \mathrm{mM}$ gold salt solutions produce GNPs of around $25 \mathrm{~nm}$, while the sizes of GNPs formed with $0.6,1.2$, and $2 \mathrm{mM}$ $\mathrm{HAuCl}_{4}$ solutions are about 17,16 , and $20 \mathrm{~nm}$, respectively. These results correlate to some of the data reported by Kimling et al. [6] in which they find that gold salt concentrations above $0.8 \mathrm{mM}$ lead to a size increase of the formed GNPs (in their case, when using Ct/Au ratios mostly up to 2:1). We also observe this tendency of size increase at higher $\mathrm{Ct} / \mathrm{Au}$ ratios when the gold salt concentrations increase over $0.8 \mathrm{mM}$, but this increase in GNP size is minimal at $\mathrm{Ct} / \mathrm{Au}$ ratios around 6:1 and is enhanced as the $\mathrm{Ct} / \mathrm{Au}$ ratios move away from 6:1.

\section{Effect of $\mathrm{pH}$}

The $\mathrm{pH}$ of the reacting mixture (gold salt + citrate) has an important role in the formation of the gold nanoparticles, as discovered by Ji et al. [5]. They reported that initial solutions with different $\mathrm{Ct} / \mathrm{Au}$ ratios displayed different $\mathrm{pH}$ values, which affected the reaction mechanism of the nanoparticles formation. It was found that $\mathrm{pH} \geq 6.5$ led to more monodisperse gold nanoparticles through a reaction mechanism which did not involve aggregates as intermediates (unlike those found in Frens' method). These studies were done with $\left[\mathrm{Au}^{3}\right.$ $\left.{ }^{+}\right]=0.25 \mathrm{mM}$ using $\mathrm{Ct} / \mathrm{Au}$ ratios of $0.7: 1$ to $28: 1$, corresponding to a $\mathrm{pH}$ range of 3.7 to 7.7 , respectively. By comparison, our studies were performed with $\mathrm{Ct} / \mathrm{Au}$ ratios of 2:1 to $14: 1$ which corresponds to a $\mathrm{pH}$ range of 4.1 to 6.8 , respectively (different concentrations led to small variations in 

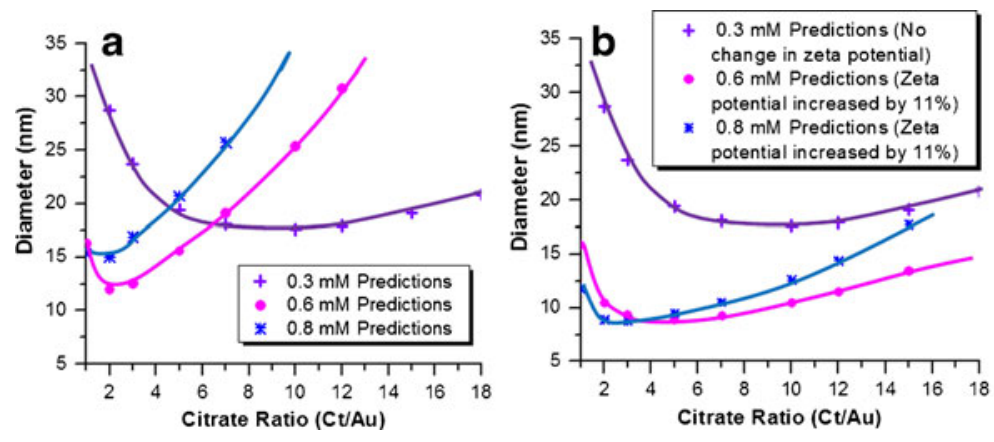

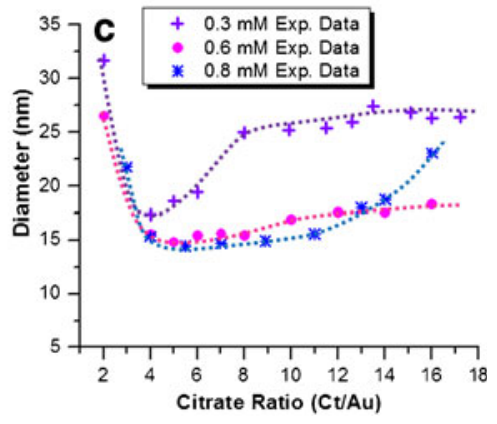

Fig. 7 Comparisons of experimental data and simulations for the sizes of GNPs from $0.3,0.6$, and $0.8 \mathrm{mM}$ initial $\left[\mathrm{Au}^{3+}\right]$. a Predictions obtained using the model of Kumar et al. [24] without modifications; b Predictions obtained using the model of Kumar et al. [24] in which the zeta potential was increased by $11 \%$ for GNPs from 0.6 and $0.8 \mathrm{mM}\left[\mathrm{Au}^{3+}\right]$; c Experimental data. The lines are guides for the eye
$\mathrm{pH}$, Table $\mathrm{S} 10$ of the ESM). Our results with $\left[\mathrm{Au}^{3+}\right]=0.3 \mathrm{mM}$ (Fig. 3) show a comparable size trend vs $\mathrm{Ct} / \mathrm{Au}$ than observed by Ji et al. [5] (i.e., size decrease followed by size increase and level off). This similarity is expected since the gold(III) concentration of $0.3 \mathrm{mM}$ is very close to Ji et al. conditions $(0.25 \mathrm{mM})$ [5]. The size trend we obtained for $\left[\mathrm{Au}^{3+}\right]=0.6 \mathrm{mM}$ also presents a size decrease followed by a size increase (Fig. 3), but the increase is minimal and the size quickly levels off at high $\mathrm{Ct} / \mathrm{Au}$ ratios. With regards to the polydispersity, the low PDI values that we observe at high $\mathrm{Ct} / \mathrm{Au}$ ratios (i.e., high $\mathrm{pH}$ ) for $\left[\mathrm{Au}^{3+}\right]=0.3$ and $0.6 \mathrm{mM}$ (Fig. 1) are in accordance with the findings of Ji et al. [5], which showed that higher $\mathrm{pH}(>6.5)$ led to more monodisperse nanoparticles. However, the GNPs that we obtained for gold(III) concentrations over $0.6 \mathrm{mM}$ did not display anymore low PDI at high $\mathrm{Ct} / \mathrm{Au}$ ratios (Figs. 1 and 2), even though the $\mathrm{pH}$ of the solutions at these high ratios were over 6.5 (Table S10 of the ESM). This seems to indicate that, at high gold(III) concentrations and high $\mathrm{Ct} / \mathrm{Au}$ ratios, the total electrolyte concentration counterbalances the effect of the $\mathrm{pH}$ and favors agglomeration. Further studies are needed to investigate this hypothesis.

\section{Modeling}

The model of Kumar et al. [24] was used to predict the sizes of GNPs obtained from initial gold chloride solutions of 0.3 to $2 \mathrm{mM}$, respectively. One should note that the complex nature of the GNP synthesis process, as brought out in the recent experimental findings [24], including those of the present work, and poor quantitative understanding of electrical interactions at high electrolyte concentration brings limitations to the model. In view of these complexities, the model is used only to obtain a physical insight into the synthetic process for the expanded set of experimental conditions. When the original model is used with no further modifications, only the predicted sizes of GNPs from $0.3 \mathrm{mM}$ initial gold(III) solutions show some qualitative agreement with the experimental data, although displaying a lower asymptotic behavior than in the experimental trend observed. In order to better predict the sizes of GNPs from initial $\left[\mathrm{Au}^{3+}\right]>0.3 \mathrm{mM}$, the expression of the surface potential in the original model was altered. Indeed, Zukoski's data [27] have shown that when citrate concentrations are increased, the measured electrophoretic mobilities suggest larger zeta potentials.

As shown in Fig. 7, an increase in zeta potential (with respect to the original value) by $11 \%$ in the model of Kumar et al. [24] leads to an improvement in the predictions of the GNP sizes. Indeed, the residuals (Fig. S2 of the ESM) are overall smaller for the predictions using a zeta potential increase of $11 \%$ than for the ones using a zeta potential increase of only $5.5 \%$, especially in the case of $\left[\mathrm{Au}^{3+}\right]=0.6$
Fig. 8 Comparisons of experimental data and simulations for the sizes of GNPs from 1, 1.2, 1.5, and $2 \mathrm{mM}$ initial $\left[\mathrm{Au}^{3+}\right]$. a Predictions obtained using the model of Kumar et al. [24] in which the zeta potential was increased by $11 \%$ for all initial $\left[\mathrm{Au}^{3+}\right]$; b Experimental data. The lines are guides for the eye
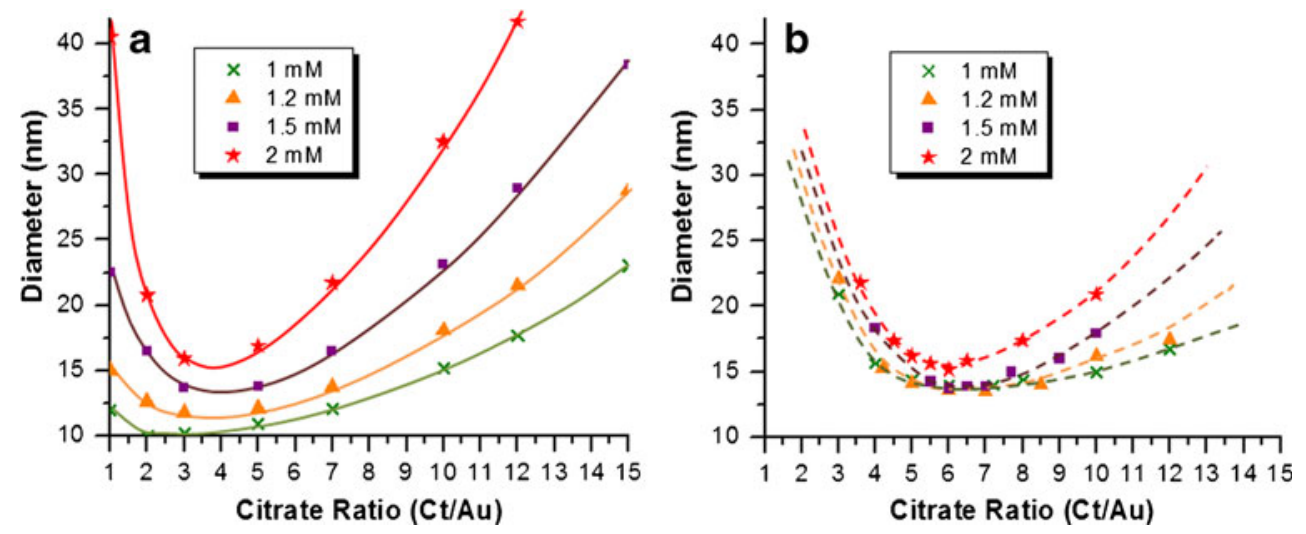
and $0.8 \mathrm{mM}$. The small differences of 2 to $5 \mathrm{~nm}$ can actually be explained by the fact that the model predicts core sizes of the GNPs while the experimental data correspond to HDs, which are always few nanometers larger than the core size. For the $0.6 \mathrm{mM}$ data set, both the slow increase in size at high $\mathrm{Ct} / \mathrm{Au}$ ratio and the smaller diameters (compared to the $0.3 \mathrm{mM}$ data set) are well captured. The increase in size of GNPs from $0.8 \mathrm{mM}$ over the ones from $0.6 \mathrm{mM}$ at high $\mathrm{Ct} /$ $\mathrm{Au}$ ratios is also correctly predicted. The predictions for GNP sizes from $0.3 \mathrm{mM}$ initial $\left[\mathrm{Au}^{3+}\right]$ could not be improved by modifying the surface potential: this can be explained by the fact that, at this low electrolyte concentration, particles are stabilized against coagulation through double layer repulsion and an increase in zeta potential does not promote further stabilization.
Figure 8 shows a comparison of model predictions (for surface potential increased by $11 \%$ ) with the experimental data for initial $\left[\mathrm{Au}^{3+}\right]$ ranging from 1 to $2 \mathrm{mM}$. The figure shows that the model accurately describes the trends found experimentally: the slope of the data set increases as the initial $\left[\mathrm{Au}^{3+}\right]$ increases, and all the trends display a minimum approximately around the same $\mathrm{Ct} / \mathrm{Au}$ ratio. The minimum size of GNPs from $2 \mathrm{mM}$ gold(III) solutions being larger than the minima observed for GNPs from 1, 1.2, and $1.5 \mathrm{mM}$ gold salt solutions is also well captured. The large differences in predicted sizes vs experimental data at high $\mathrm{Ct} / \mathrm{Au}$ ratios are attributed to the limitations of the model at high electrolyte concentration. Briefly, in our model, the calculation of stability factor for DLVO theory at high electrolyte concentration and in presence of a host of ionic
Fig. 9 TEM images of GNPs obtained from starting $\left[\mathrm{Au}^{3+}\right]$ of $0.3,0.6,1.2$, and $2 \mathrm{mM}$ and using $\mathrm{Ct} / \mathrm{Au}$ ratios of $4: 1,6: 1$, and 10:1. The scale bars represent $20 \mathrm{~nm}$

\section{Ct/Au Ratios}

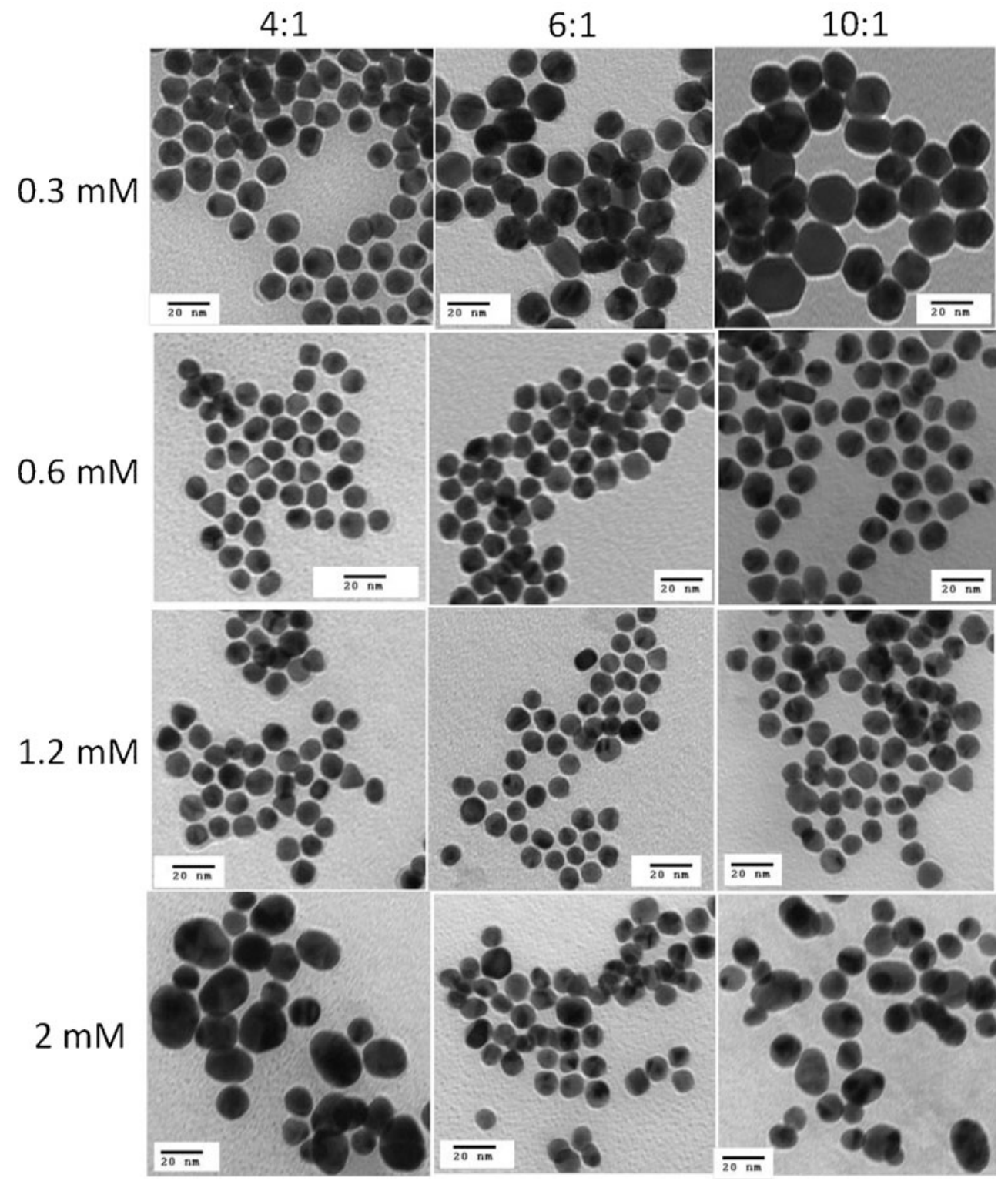


species in the system is based on a semi-empirical approach validated for the low concentrations used in the original Turkevich protocol. The model is therefore used here to qualitatively understand the experimental observations made in the present work under expanded set of experimental conditions.

Relationship between the evolution of GNP sizes and their respective PDI

Interestingly, for each initial concentration of gold chloride solution, the evolution of the GNP diameter as a function of $\mathrm{Ct} / \mathrm{Au}$ ratio follows a similar trend as to the evolution of its PDI. Consequently, for gold(III) solutions below $0.8 \mathrm{mM}$, the largest monodisperse GNPs $(\mathrm{PDI}<0.1)[25,26,28]$ have a polydispersity curve that reaches a plateau at high $\mathrm{Ct} / \mathrm{Au}$ ratios. For instance, the largest HD that can be obtained from 0.3 and $0.6 \mathrm{mM}$ gold(III) solutions in a monodisperse manner are about 27 and $18 \mathrm{~nm}$, respectively. However, for initial $\mathrm{HAuCl}_{4}$ concentrations above $0.8 \mathrm{mM}$, the increase in the particle size at higher $\mathrm{Ct} / \mathrm{Au}$ ratios is associated with an increase in PDI. When drawing an imaginary line at PDI of 0.1 in Fig. 2, the PDI curve is intercepted twice for a given initial gold(III) concentration: the corresponding values of $\mathrm{Ct} /$ $\mathrm{Au}$ ratios can be used in Fig. 4 to determine the maximum monodisperse sizes from this concentration. The increase in $\mathrm{PDI}$ at higher gold salt concentrations and higher $\mathrm{Ct} / \mathrm{Au}$ ratios is most probably due to the increase in ionic strength which contributes to a higher propensity of the nanoparticles for agglomeration.

The sizes and size distributions of GNPs were also measured by TEM to verify the trends observed by DLS. Samples of GNPs with initial gold(III) concentrations of $0.3,0.6$, 1.2 , and $2 \mathrm{mM}$ were selected. For each of these concentrations, TEM images were taken for $\mathrm{Ct} / \mathrm{Au}$ ratios of $4: 1,6: 1$, and 10:1. The mean sizes and size distributions were measured for each of the 12 samples (Fig. 9) and compared with the values observed by DLS. As expected, the diameters measured by TEM were consistently smaller than the HD measured by DLS (in solution). However, the general trends in sizes and size distributions found from the TEM data correlated well with those observed by DLS. For instance, samples with $\mathrm{Ct} / \mathrm{Au}$ ratios of $6: 1$ gave the narrowest standard deviations for gold(III) concentrations of 0.3 and $0.6 \mathrm{mM}$ (6.8 and $7.4 \%$, respectively). Also, a larger mean size was measured for GNPs from $0.3 \mathrm{mM}$ gold salt solutions $(15.4 \mathrm{~nm})$ than for GNPs from $0.6 \mathrm{mM}$ gold salt solutions $(12.0 \mathrm{~nm})$. Furthermore, the GNPs from $2 \mathrm{mM}$ gold salt solutions and $\mathrm{Ct} / \mathrm{Au}$ ratio of 10:1 showed the largest standard deviation (24.7\%) out of all the samples studied by TEM, which matches with the highest PDI observed by DLS for this sample.

\section{Conclusion}

By extending the conditions of the Turkevich-Frens method, it has been found that two groups of gold chloride concentrations present two different behaviors as a function of the $\mathrm{Ct} /$ $\mathrm{Au}$ ratios. Gold salt solutions below $0.8 \mathrm{mM}$ lead to the formation of highly monodisperse GNPs for $\mathrm{Ct} / \mathrm{Au}$ ratio over 4:1. The size of the formed GNPs presents a minimum at $\mathrm{Ct} /$ Au ratios around 4:1-5:1 and saturates at high ratios $(>10: 1)$. However, gold salt solutions over $0.8 \mathrm{mM}$ lead to the formation of monodisperse GNPs ( $\mathrm{PDI}<0.1)[25,26,28]$ only for a certain range of $\mathrm{Ct} / \mathrm{Au}$ ratios, which becomes narrower as the concentration of gold(III) increases. Also, the size of these GNPs presents a minimum at specific $\mathrm{Ct} / \mathrm{Au}$ ratios, but increases unboundedly at high ratios, accompanied by an increase of the corresponding PDI. It can be concluded that the increase in ionic strength induced by the high concentration of gold salt has a significant impact on both the size and size distribution of the formed GNPs, especially for $\mathrm{HAuCl}_{4}$ solutions over $0.8 \mathrm{mM}$. The model of Kumar et al. [24], initially tested against the experimental data obtained for the original Turkevich protocol using $0.3 \mathrm{mM}$ initial gold chloride concentration, is tested for the expanded protocol conditions. The model captures the experimental observations for the expanded operational range (concentration ranging from 0.3 to $2.0 \mathrm{mM}$ ) quite well. The model also brings out the sensitive dependence of particle synthesis process to small variations in zeta potential of particles.

Acknowledgments The authors are grateful to Dr. Tiberiu-Dan Onuta for his very helpful suggestions and comments on this work, as well as for the creation of the residual data in Figure S2 of the ESM. We also acknowledge the financial support from the Department of Defense (Prostate Cancer Research Program, CDRMP, grant no. PC081299).

Open Access This article is distributed under the terms of the Creative Commons Attribution License which permits any use, distribution and reproduction in any medium, provided the original author(s) and source are credited.

\section{References}

1. Turkevich J, Stevenson PC, Hillier J (1951) Discuss Faraday Soc 11:55-75

2. Frens G (1972) Kolloid-Z Z Polym 250:736-741

3. Frens G (1973) Nature (London) Phys Sci 241:20-22

4. Hayat MA (eds) (1989) Colloidal Gold: principles, methods, and applications, Vol. 1. Academic

5. Ji X, Song X, Li J, Bai Y, Yang W, Peng XJ (2007) Am Chem Soc 129:13939-13948

6. Kimling J, Maier M, Okenve B, Kotaidis V, Ballot H, Plech AJ (2006) Phys Chem B 110:15700-15707

7. Daniel M-C, Astruc D (2004) Chem Rev (Washington, DC, U S) 104:293-346 
8. Fathi-Azarbayjani A, Qun L, Chan YW, Chan SY (2010) AAPS PharmSciTech 11:1164-1170

9. Lee J-S, Cho J, Lee C, Kim I, Park J, Kim Y-M, Shin H, Lee J, Caruso F (2007) Nat Nano 2:790-795

10. Bowman M-C, Ballard TE, Ackerson CJ, Feldheim DL, Margolis DM, Melander C (2008) J Am Chem Soc 130:6896-6897

11. Daniel M-C, Grow ME, Pan H-M, Bednarek M, Ghann WE, Zabetakis K, Cornish J (2011) New J Chem 35:2366-2374

12. Bresee J, Maier KE, Boncella AE, Melander C, Feldheim DL (2011) Small 7:2027-2031

13. Hainfeld JF, Slatkin DN, Focella TM, Smilowitz HM (2006) Br J Radiol 79:248-253

14. Ghann WE, Aras O, Fleiter T, Daniel MC (2012) Langmuir 28:10398-10408

15. Boisselier E, Astruc D (2009) Chem Soc Rev 38:1759-1782

16. Bresee J, Maier KE, Melander C, Feldheim DL (2010) Chem Commun (Cambridge, U K) 46:7516-7518

17. Xia T, Kovochich M, Brant J, Hotze M, Sempf J, Oberley T, Sioutas C, Yeh JI, Wiesner MR, Nel AE (2006) Nano Lett 6:1794-1807
18. Dreher KL (2004) Toxicol Sci 77:3-5

19. Bergen JM, von Recum HA, Goodman TT, Massey AP, Pun SH (2006) Macromol Biosci 6:506-516

20. Gaumet M, Vargas A, Gurny R, Delie F (2008) Eur J Pharm Biopharm 69:1-9

21. Ojea-Jimenez I, Bastus NG, Puntes VJ (2011) Phys Chem C 115:15752-15757

22. Sivaraman SK, Kumar S, Santhanam VJ (2011) Colloid Interface Sci 361:543-547

23. Li C, Li D, Wan G, Xu J, Hou W (2011) Nanoscale Res Lett 6:440

24. Kumar S, Gandhi KS, Kumar R (2007) Ind Eng Chem Res 46:3128-3136

25. Nobbmann U, Connah M, Fish B, Varley P, Gee C, Mulot S, Chen J, Zhou L, Lu Y, Shen F, Yi J, Harding SE (2007) Biotechnol Genet Eng Rev 24:117-128

26. Zhang C, Chung JW, Priestley RD (2012) Macromol Rapid Commun 33:1798-1803

27. Chow MK, Zukoski CFJ (1994) Colloid Interface Sci 165:97-109

28. http://www.malvern.com; FAQ: What does polydispersity mean? 